\title{
Susan G Komen Breast Cancer Foundation
}

National Cancer Institute

\section{Source}

National Cancer Institute. Susan G Komen Breast Cancer Foundation. NCI Thesaurus.

Code C39524.

The Susan G. Komen Breast Cancer Foundation is the Dallas-based non-profit

org anization dedicated support of innovative breast cancer research and community-

based outreach programs. The Komen Foundation fulfills its mission by funding research grants and supporting education, screening and treatment projects in communities around the world. 